Como citar este artículo en APA: Martínez Sáez, Juan F. (2020). Animación misionera en el magisterio pontificio y la pastoral. Cuestiones Teológicas, 47 (108), 78-101. doi: http://doi.org/10.18566/cueteo.v47n108.a05

Fecha de recepción: 30.07.2020 / Fecha de aceptación: 21.10.2020

\title{
ANIMACIÓN MISIONERA EN EL MAGISTERIO PONTIFICIO Y LA PASTORAL
}

\author{
Missionary Animation within Pontifical Magisterium and Pastoral
}

Juan F. Martínez SÁez, FMVD

\section{Resumen}

El magisterio del papa Francisco es una clara convocatoria a cada uno de los bautizados, y a la Iglesia en su conjunto, a constituirse en un "estado permanente de misión”. Esta contribución presenta una síntesis del magisterio y la práctica pastoral pontificios desde antes del Concilio Vaticano II hasta el actual sucesor de Pedro, con relación a la animación misionera como instrumento pastoral para que los bautizados participen en la misión de la Iglesia. La intención es mostrar cómo la idea de que el espíritu universal y misionero del evangelio corresponde a todos los bautizados se ha ido extendiendo progresivamente en la Iglesia con el objetivo de llegar a que sea la autocomprensión habitual de los cristianos y de las comunidades cristianas. A ello ha contribuido tanto el magisterio de los papas como su práctica pastoral con respecto a la Iglesia universal, en particular a través de las Obras Misionales Pontificias (OMP), así como otras iniciativas carismáticas ligadas a instituciones de carácter misionero. Así, se ha ido perfilando de manera gradual el concepto teológico-pastoral de animación misionera, su sentido y su metodología. El recorrido histórico de pontificados anteriores al papa Francisco hace comprender que él, aunque prescinda del uso literal de la expresión animación misionera, a la vez implementa su contenido y sus formas en su magisterio, sus palabras, sus gestos y sus acciones, así como su ministerio pastoral hacia la Iglesia universal para que todo bautizado sea discípulo misionero y dé esperanza fundada en "una nueva etapa evangelizadora.

Palabras clave: Misionología; Teología de la Misión; Magisterio Eclesiástico; Animación Misionera; Pastoral; Conversión Misionera; Papa Francisco; Espiritualidad Misionera; Discípulo Misionero.

1 Doctor in utroque iure por la Pontificia Universidad Lateranense - Roma, Italia. Profesor de Derecho Canónico en el Instituto Teológico Verbum Dei, Loeches-Madrid, España. Cátedra de Misionología de la Facultad de Teología de la Universidad Eclesiástica San Dámaso - Madrid, España. Correo electrónico: juan.martinez@itvdsanpablo.com 


\section{Abstract}

The magisterium of Pope Francis is a clear call to every single baptized catholic and the whole Church to be in a "permanent state of mission". The article presents a summary of the pontifical magisterium and pastoral practices from before Second Vatican Council to the current Pope regarding missionary animation as pastoral instrument for every baptized person to participate in the mission of the Church. It aims at showing how the idea that the universal and missionary spirit of the Gospel is a responsibility of every baptized catholic has been strengthened within the Church with the purpose that it becomes the common self-understanding of Christians and Christian communities. Both the pontifical magisterium and pastoral practices of the popes concerning universal Church have contributed to this idea, particularly through the Pontifical Mission Societies and other charismatic initiatives linked to missionary institutions. Thus, the theological-pastoral concept of missionary animation has gradually been developed, both in meaning and method. The historical overview makes possible to understand that though Pope Francis does not literally use the expression missionary animation, he does introduce its content and forms into his magisterium, gestures, and actions; as well as into his pastoral magisterium towards the universal Church, so every baptized person becomes a missionary disciple and provides hope based on "a new chapter of evangelization".

Keywords: Missiology; Mission Theology; Ecclesiastical Magisterium; Missionary Animation; Pastoral; Missionary Conversion; Pope Francis; Missionary Spirituality; Missionary Disciples.

\section{Introducción}

Es indudable que el Concilio Vaticano II supuso un cambio trascendental en la autocomprensión de la Iglesia. El número de obispos convocados, la intervención activa de obispos originarios de los continentes de América, África y Asia y el asesoramiento de importantes teólogos aportó una visión universal de la Iglesia, tal y como corresponde a su naturaleza íntima. Así se reflejó en sus documentos, ya que esta se había opacado, a lo largo de los siglos, por visiones localistas, nacionalistas y colonialistas. El Concilio Vaticano II constata el fin de un mundo eurocéntrico y colonialista, trasladando a la Iglesia la visión de un mundo en el que, cada vez más, priman las relaciones multilaterales entre personas, pueblos y naciones.

El fin de una visión colonial del mundo no significa la inmediata desaparición de la mentalidad colonial en todas las personas; la creciente interrelación entre personas y pueblos no implica que los efectos positivos de la globalización sean queridos y fomentados por todos, así como combatidos los negativos. Del mismo modo, la clara afirmación de la universalidad de la Iglesia no conlleva, de modo automático, a una mentalidad abierta y misionera. El empeño de los papas del postconcilio en este sentido ha sido enorme, con palabras y obras. La llegada, por primera vez en la historia de un latinoamericano a la Sede de Pedro, ha sido un acontecimiento inesperado y de gran trascendencia: su empeño, con nuevas formas pastorales, por impregnar a los bautizados y a la Iglesia universal con una nueva visión de sí misma, y un decidido empeńo por la obra de la evangelización universal, no necesita comentario. 
El objetivo de este estudio es mostrar la tenacidad de los papas desde el inicio del siglo pasado en fomentar una visión cada vez más universal de la Iglesia. En el magisterio pontificio es constante la idea de que de la conciencia de la universalidad de la Iglesia se debe desprender el compromiso con su actividad misionera. De esta manera, a lo largo de los siglos se ha fraguado el concepto de animación misionera. En consecuencia, se busca precisar el concepto teológico-pastoral de animación misionera y el uso pastoral que de él han hecho los papas. Finalmente, como fruto de los resultados de la investigación, se pretende aportar para la comprensión del magisterio del papa Francisco y de la llamada que lanza a los bautizados, y a toda la Iglesia, para vivir en estado de misión.

El método que se va a seguir es el del examen de las fuentes del magisterio universal en referencia al tema de este trabajo. No se pretende un estudio acerca de la misión de la Iglesia ni de la misión ad gentes, sobre las que existe una amplia literatura; se examinan solamente aquellas afirmaciones magisteriales que hacen referencia — explícita o implícita - a la animación misionera. Otra importante acotación es la limitación al magisterio pontificio, sin tomar en consideración otras fuentes magisteriales.

La razón para ello es que, al estudiar el magisterio pontificio acerca de la dimensión misionera de la Iglesia, lo primero que salta a la vista es que, a partir de cierto momento, se ha utilizado frecuentemente la expresión animación misionera sin haber ofrecido, en realidad, previamente, una definición, sino que, por el contrario, se daba por sabido de qué se hablaba cuando se mencionaba. Con la ayuda de la práctica de la pastoral misionera el magisterio ha ido clarificando el concepto para irlo insertando, cada vez más, en la conciencia y en la vida pastoral de las diócesis y comunidades cristianas.

En este estudio se pretende hacer un sucinto recorrido histórico de las fuentes del magisterio pontificio y de la práctica pastoral de los papas con el objetivo de comprobar el desarrollo que ha tenido, especialmente en los últimos pontífices. Ciertamente, el estudio no puede ser exhaustivo, por lo que está limitado a las contribuciones que se consideran más significativas para el objetivo propuesto.

El presupuesto que da origen a esta investigación es que, desde los inicios del siglo pasado, la Iglesia ha vivido un profundo impulso misionero que ha llevado a una más plena conciencia de su naturaleza misionera, así como de los instrumentos necesarios para la colaboración de todos los fieles en la evangelización universal. En este proceso, la contribución de los pontífices romanos, su estímulo y acompañamiento ha sido un factor decisivo.

El actual sucesor de Pedro pide que este proceso se extienda a toda la Iglesia y que todos los bautizados tengan la conciencia de ser discípulos misioneros. En este artículo se investigan las premisas de orden magisterial que sostienen la pretensión y se sostiene que, aunque no haga una referencia explícita a la animación misionera, Francisco, de un modo novedoso, — propio de la Iglesia en América latina-insiste en concienciar a los bautizados para participar en la misión universal de la Iglesia.

Metodológicamente hay que distinguir entre las prácticas pastorales que fomentan la conciencia misionera de los fieles y la conceptualización teológica, que es posterior, cronológicamente. Por este motivo, se intenta mostrar cómo el magisterio misionero ha sido acompañado de iniciativas pastorales de índole misionera. 
Se parte del estado de la cuestión en el magisterio anterior al Concilio Vaticano II para comprobar su desarrollo posterior en el propio concilio y el magisterio pontificio postconciliar, así como la práctica pastoral pontificia; especial atención se dedica al actual Obispo de Roma por la originalidad de su propuesta. Finalmente, se avanzan las conclusiones que se consideran oportunas para la investigación teológica y para la práctica pastoral.

\section{Magisterio anterior al Concilio Vaticano II}

Con anterioridad al Concilio Vaticano II los papas dan por descontado que el cristiano sabe que la Iglesia es universal y que, por el bautismo, tiene un papel que desempeñar para que el anuncio del evangelio se extienda por todo el mundo y alcance a todos los hombres y pueblos. En consecuencia, el magisterio pontificio misionero insiste en la necesidad de recordar esta realidad a todos los cristianos. Para ello, Benedicto XV, en 1919, en la primera encíclica misionera, Maximum illud, apela a cumplir "con su obligación como es debido" (1919, 109). En 1926, en la encíclica Rerum Ecclesiae, Pío XI expone, en primer lugar, el interés de la Iglesia por las misiones y declara, con vehemencia, su propia preocupación por "esta obligación de nuestro oficio pastoral" $(1926,17)$; fundamenta la obligación de todo creyente con las misiones en tres pilares: el amor a Dios, el amor al prójimo y la gratitud por el don de la fe.

Una importante decisión práctica de Pío XI en 1922, con motivo del centenario de la Obra de Propagación de la Fe, fue la elevación de las obras misionales a la categoría de pontificias (Propagación de la Fe, Santa Infancia y San Pedro), fundadas por iniciativa carismática de algunos fieles en el siglo XIX, en Francia, y el traslado de los respectivos secretariados generales a Roma, como muestran Trinchese (1996) y Soetens (1996). A partir de este momento, los papas se han servido de ellas como el instrumento privilegiado para la animación y cooperación misioneras. Se les unirá, en 1956 —en el carácter pontificio- la Unión Misional del Clero, que había sido fundada por el beato Paolo Manna en 1916.

Sin embargo, hay que constatar que hasta Pío XII predominan las motivaciones de tipo moral para la misión. Con la encíclica Mystici corporis Christi, de 1943, la cuestión da un giro decisivo porque se acentúa mucho más el carácter espiritual. La Iglesia es el Cuerpo de Cristo animado por el Espíritu Santo; a su vida y crecimiento contribuyen todos los miembros, quienes contribuyen, cada uno a su manera, a la edificación del Cuerpo. La acción vivificadora y santificante del Espíritu Santo es el principal motor; pero no basta que el Cuerpo Místico esté animado por el Espíritu Santo, ya que la vía ordinaria por la que crece es por la acción y cooperación de todos los miembros, secundando el impulso de vida que viene del Espíritu².

2 Esta doctrina tiene su origen en san Agustín y se encuentra presente en el CV II: "[Cristo] nos concedió participar de su Espíritu, quien, siendo uno solo en la Cabeza y en los miembros, de tal modo vivifica todo el cuerpo, lo une y lo mueve, que su oficio pudo ser comparado por los Santos Padres con la función que ejerce el principio de vida o el alma en el cuerpo humano" (Concilio Vaticano II, 1964, 7). Originariamente fue expresada por el Cardenal Benlloch, arzobispo de Burgos, en su famosa carta pastoral dela 3 de diciembre de 1920, y desarrollada ampliamente por la "escuela espańola" de misionología, especialmente por el P. Zameza, como explica Santos (1977). Por otro lado, dice Seumois (1961): "El apostolado misionero, aunque sea practicado por hombres, es sin embargo una obra enteramente sobrenatural y divina” (p. 5). 
Más tarde, Pío XII en la encíclica Fidei donum, publicada en 1957, pide "fomentar el fervor apostólico de los cristianos, que se han vuelto más conscientes de los deberes que exige la fe recibida de Dios" (2); para ello invita a la oración, a la generosidad y a la entrega de sí mismos (13). Este fervor solo puede provenir de "una condición de espíritu, una generosidad de alma [...] Una generación formada en estos ideales verdaderamente católicos [...] una atmósfera favorable a esta causa" (15). San Juan XXIII, en 1959, en la encíclica Princeps pastorum, recuerda que "nunca será bastante cuanto hagamos" (2), e insiste en que "nos apremia la urgente necesidad de procurar la salvación de las almas” (3).

\section{El Concilio Vaticano Il y el decreto Ad Gentes}

El Concilio Vaticano II (CV II) encuentra una de sus inspiraciones en la misma urgencia misionera y la consecuente responsabilidad o deber por las misiones junto con la motivación espiritual necesaria para este fin. De hecho, el capítulo VI del decreto Ad Gentes (Concilio Vaticano II, 1965a), dedicado a la cooperación misionera, se abre con un párrafo introductorio en el que afirma que la cooperación es el "deber fundamental del pueblo de Dios” por la evangelización (Concilio Vaticano II, 1965a, 35). Sin embargo, toma un cariz más allá del deber moral, ya que apela a una "profunda renovación interior" porque así "teniendo una viva conciencia de la responsabilidad propia en la difusión del Evangelio, asuman [todos] su papel en la obra misionera entre los gentiles" (ibid.). En el número siguiente se desarrolla esta misma idea y, a continuación, lo aplica a las diversas realidades de la Iglesia.

En el primer párrafo del numeral 36 del documento Ad Gentes (Deber misionero de todo el Pueblo de Dios), se recuerda a todos los fieles que son miembros de Cristo por los sacramentos de la iniciación cristiana, lo que conlleva el deber de "cooperar a la expansión y dilatación del Cuerpo de Cristo para llevarlo cuanto antes a su plenitud" (36) Se trata, pues, de un deber que se corresponde con la vida que el Espíritu infunde en el Cuerpo Místico de Cristo. En AG, siempre el mandato formal de Cristo de llevar el evangelio por todo el mundo está en correspondencia con la vida del Espíritu.

El segundo párrafo insiste en que los fieles han de tener "viva conciencia de su responsabilidad para con el mundo" (36), para así fomentar "un espíritu verdaderamente católico y consagrar sus energías a la obra de evangelización" (ibid.). Advierte, sin embargo, que la "primera y principal obligación en pro de la difusión de la fe es vivir profundamente la vida cristiana" (ibid.), porque de ello se sigue "un nuevo aliento espiritual a toda la Iglesia" (ibid.) que la convertirá en auténticamente misionera: signo, luz y sal. Es de destacar que el Concilio pone de manifiesto que existe una continuidad entre la pastoral ordinaria, (que tiene como objetivo vivir cada vez más plenamente la vida cristiana) y la misión universal. Consecuencia de este "espíritu renovado" (36), es decir, plenamente misionero, afirma el CV II que "se ofrecerán espontáneamente a Dios oraciones y obras de penitencia para que fecunde con su gracia la obra misionera, surgirán vocaciones misioneras y brotarán los recursos que las misiones necesitan" (36), es decir, los medios clásicos de la cooperación misionera espiritual, personal y económica. Los dos últimos párrafos insisten en una importante actividad humana, necesaria para crear conciencia misionera: la información. Conocer las noticias misioneras, empuja a los creyentes en Cristo a sentir como propia la actividad misionera, a abrir el corazón a sus necesidades y a socorrerlas. 
A continuación, AG explicita el Deber misionero de las comunidades cristianas (37), para luego detallar las peculiaridades de todos los miembros del Pueblo de Dios. Esto no está en contradicción con el carisma, espíritu y labor de las Obras Misionales Pontificias (OMP), sino que, al contrario, "deben ocupar con todo derecho el primer lugar, pues son medios para infundir a los católicos, ya desde la infancia, el sentido verdaderamente universal y misionero y para estimular la recogida eficaz de ayudas en favor de todas las misiones, según las necesidades de cada una" (38). Hay que resaltar el tono espiritual que tiene siempre la concreción del deber misionero. El fundamento es la "caridad hasta los confines de la tierra" (37), "el ardor misionero" (38), "el celo por la evangelización” (39) y "el conocimiento y el amor a las misiones" (41).

\section{Magisterio pontificio postconciliar}

En el magisterio pontificio posterior al Concilio Vaticano II existe, lógicamente, una profunda continuidad con la doctrina de éste, desarrollando lo que en él se encuentra de manera germinal.

\subsection{El magisterio de san Pablo VI}

San Pablo VI, en el motu proprio de las normas para la aplicación de algunos decretos del CV II, Ecclesiae sanctae, publicadas en 1966, dedica la tercera parte al decreto AG. Ahí se insiste en que "todo el Pueblo de Dios llegue a ser consciente de su obligación misionera" (Pablo VI, 1966a, III, Proemio) y en los medios necesarios para ello: la formación, la oración, los sacrificios cotidianos, la colecta anual, etc. También, insta a la constitución de una Comisión Episcopal de Misiones, encargada de "fomentar la actividad y conciencia misionera y la organización concorde de la cooperación" (Pablo VI, 1966a, III, 9). Posteriormente, en 1969, el decreto de la Sagrada Congregación para la Evangelización de los Pueblos o de Propaganda Fide, Quo aptius, insiste en el espíritu y las propuestas del magisterio pontificio, en particular, señala como la primera función de la Comisión Episcopal de Misiones "favorecer las iniciativas que estimulen en el Pueblo de Dios, sobre todo en el clero, la conciencia del deber misionero y la actividad por las misiones" (Sagrada Congregación para la Evangelización de los Pueblos o de Propaganda Fide, 1969, 6. a).

En la instrucción Postquam Apostoli (1980), se resalta que la función de las Comisiones Episcopales del Clero y de Misiones es "informar de las necesidades" y "hacer cada vez más conscientes a los fieles de su responsabilidad y desarrollar en ellos el sentido de la catolicidad a través de una madura y activa colaboración de las Iglesias particulares" (Sagrada Congregación para el Clero, 1980, 22).

De acuerdo con el espíritu del Concilio Vaticano II de devolver a las iglesias particulares el protagonismo que deben tener, se constata como en la aplicación de los principios doctrinales del decreto AG se pretende, claramente, que ellas (las diócesis y conferencias episcopales) sean también el motor de la animación y cooperación misioneras, así como también se enfatiza la responsabilidad de los pastores en la animación misionera.

En este sentido, es interesante que la carta apostólica Graves et increscentes, escrita por san Pablo VI en 1966 con motivo de los 50 años de la fundación de la Pontificia Unión Misional, resalta el deber concreto de los sacerdotes en cuanto pastores del pueblo de Dios que deben ayudarle a vivir su responsabilidad misionera: 
Por tanto, es deber propio y gravísimo de los sacerdotes diocesanos ayudar al Pueblo de Dios a formarse una recta y plena conciencia de la Iglesia, entendida como cuerpo vivo formado de miembros entre sí estrechamente ligados, a fin de que cada uno sepa asumir en la vida de la Iglesia, con valor y responsabilidad, el puesto a él asignado por el bautismo y por la confirmación, y así la Iglesia de Dios se convierte realmente en «sacramento, o sea, signo e instrumento de la íntima unión con Dios y de la unidad de todo el género humano (Pablo VI, 1966b, 18).

\subsection{San Juan Pablo II y la Redemptoris Missio (RMi)}

Hay que esperar hasta la Redemptoris Missio (1990), de san Juan Pablo II, para que haga aparición el concepto animación misionera en el magisterio pontificio y que éste ofrezca a la Iglesia un desarrollo orgánico de qué es y cómo se realiza, aunque conceptualmente está en estrecha ligazón con la formación misionera. Lo primero a resaltar es que la formación misionera "es obra de la iglesia local" (Juan Pablo II, 1990, 83), que es "central en la vida cristiana" (Juan Pablo II, 1990, 83) y un "elemento primordial" (Juan Pablo II, 1990,83 ) de la pastoral ordinaria de las iglesias locales en todos sus ámbitos. La razón es que la misión, y en concreto el testimonio de los misioneros, tiene un gran atractivo y por tanto es de gran ayuda para la "nueva evangelización de los pueblos cristianos" (Juan Pablo II, 1990, 83).

San Juan Pablo II insiste en que el celo misionero es responsabilidad de todos los agentes de pastoral de la iglesia local, contando con la ayuda de los misioneros, de los institutos misioneros y de los miembros jóvenes de la iglesia. Especialmente importante es la formación teológica académica de la que no se puede prescindir (Juan Pablo II, 1990).

Elemento muy valioso de la animación es la información, ya que su papel es de "gran importancia" para conocer la Iglesia universal (Juan Pablo II, 1990, 83). En el mismo número insiste en que: "Las actividades de animación deben orientarse siempre hacia sus fines específicos: informar y formar al Pueblo de Dios para la misión universal de la Iglesia; promover vocaciones ad gentes; suscitar cooperación para la evangelización" (Juan Pablo II, 1990, 83) por lo que no se debe dar una "imagen reductiva de la actividad misionera" (Juan Pablo II, 1990, 83), sino mostrar su "cometido primario" (Juan Pablo II, 1990, 83), evitando mostrar solo la dimensión de desarrollo humano y social.

Antes de estudiar el concepto de animación misionera que ofrece RMi 83, hay que resaltar que:

1. la animación misionera tiene una orientación. Es decir, no se trata de un programa detallado de temas, contenidos, recursos, etc., sino de actividades pastorales dirigidas hacia un fin concreto;

2. para ello hay unos fines especificos que hay que perseguir cuando se realizan actividades pastorales de animación misionera;

3. el fin último es fomentar la actividad misionera universal de la Iglesia.

Por otro lado, cuando habla de los "fines específicos" de la animación misionera recurre a los que ya se habían hecho tradicionales: la información, la formación, la promoción de las vocaciones ad gentes y el fomento de la cooperación para la evangelización.

Con ello se puede decir que se puede dar por finalizado un ciclo en el cual se ha ido perfilando el concepto de animación misionera, se ha definido su naturaleza y su metodología propia. De esta manera, 
adquiere carta de naturaleza dentro de la teología de la misión y pastoral. La animación misionera pasa de ser una mera actividad pastoral para tener un estatuto propio y bien definido dentro de la teología. Esto debería ser suficiente para fomentar su práctica en la Iglesia universal, en las iglesias particulares y en las comunidades cristianas.

Una consecuencia de la RMi fue la publicación, en 1998, de la instrucción Cooperatio missionalis. En ella se afirma que la cooperación misionera es "el primer fruto de la animación misionera" (Congregación para la Evangelización de los Pueblos, 1998, Principios doctrinales, 2), y la entiende:

Como un espíritu y una vitalidad que impulsa a los fieles, las instituciones y las comunidades a una responsabilidad universal, formando una conciencia y una mentalidad misionera dirigida ad gentes. Por eso, toda iniciativa de animación misionera se orienta siempre a su fin: formar al Pueblo de Dios para la misión universal «específica», suscitar buenas y numerosas vocaciones misioneras y promover cualquier forma de cooperación en la evangelización (ibid.).

Entre los organismos de la cooperación misionera destaca la Congregación para la Evangelización de los Pueblos como "organismo central encargado de dirigir y coordinar la evangelización y la cooperación misionera" (Congregación para la Evangelización de los Pueblos, 1998, 3); un cometido semejante corresponde, en su respectivo ámbito local, a las respectivas Comisiones de Misiones de las Conferencias Episcopales y a los organismos diocesanos (ibid.). También recalca el "carácter prioritario de las Obras Misionales Pontificias" (5) y señala explícitamente que el cometido de la Comisión Episcopal de Misiones, además de incrementar la evangelización ad gentes, es "la animación y cooperación misionera en sus diversas formas" (10). Es importante resaltar que uno de los motivos de la instrucción es la constatación del nacimiento de Formas especiales y nuevas de cooperación misionera (Congregación para la Evangelización de los Pueblos, 1998, V.).

Coherente con el programa expresado en la RMi de crecimiento en la fe y en la conciencia misionera de las iglesias particulares, san Juan Pablo II apela, muy frecuentemente, a la necesidad de la animación misionera en los mensajes para la Jornada Mundial de las Misiones. En ellos trata de la naturaleza de la animación misionera, así como de aspectos particulares: agentes y destinarios, la formación, la información, etc.

\subsection{En Benedicto XVI}

El papa Benedicto XVI —en su breve pontificado — tiene algunas referencias muy interesantes sobre el tema en los mensajes para la Jornada Mundial de las Misiones. Su primer mensaje, el año 2006, lleva significativamente el título: La caridad, alma de la misión (Benedicto XVI, 2006) así como el mensaje del ańo siguiente: Todas las Iglesias para todo el mundo (Benedicto XVI, 2007). En el mensaje del año 2010, en clave de comunión eclesial, afirma que la celebración de la Jornada Mundial de las Misiones es "la ocasión para renovar el compromiso de anunciar el evangelio y dar a las actividades pastorales una dimensión misionera más amplia” (Benedicto XVI, 2010). El mensaje del año siguiente constata que la evangelización es un proceso complejo y comprende varios elementos - en total sintonía con lo que afirma la Evangelii nuntiandi en el numeral 24 Pablo VI, 1975, 24) - y prosigue: "Entre estos, la animación misionera ha prestado siempre una atención peculiar a la solidaridad" (Benedicto XVI, 2011). Precisamente en el mensaje del año 2012, el último, es donde afirma con claridad que "la misión ad gentes debe ser el horizonte constante y el paradigma en todas las actividades eclesiales” (Benedicto XVI, 2012). Esta última 
afirmación ha sido retomada por el papa Francisco que la reformula con las siguientes palabras: "La salida misionera es el paradigma de toda obra de la Iglesia” (Francisco, 2013a, 15).

\section{La animación misionera como práctica pastoral}

Es interesante notar que, aunque el término animación misionera aparece tardíamente de forma expresa en el magisterio pontificio - como se ha visto en la exposición anterior-, la práctica pastoral correspondiente se empieza a extender desde finales del CV II, como constata Echenique (1972) 3 . De la misma manera Esquerda Bifet $(2000)^{4}$ también afirma que:

En las encíclicas misioneras anteriores al concilio Vaticano II, “cooperación” significa la ayuda que presta la comunidad eclesial a la misión "ad gentes": oraciones, sacrificios, vocaciones, limosnas... La palabra "animación” es propiamente postconciliar y significa motivar la comunidad para conseguir esas ayudas. La "animación" (comunicar vida y espíritu) equivale a la acción pastoral dirigida a hacer misionera a la comunidad eclesial. Las dos palabras son, pues, complementarias y, en cierto sentido, equivalentes en lo esencial. La "cooperación" presupone la "animación” y la formación misionera de la comunidad. (Esquerda Bifet, 2000, p. 201)

De hecho, parece que es Pablo VI quien normaliza el uso. En el discurso a los directores nacionales de las OMP, del 19 de mayo de 1972, se expresa de la siguiente manera:

Las Obras Misionales Pontificias constituyen el principal medio a disposición de los obispos para la animación misionera del pueblo de Dios, con ello se les asigna a estas Obras un puesto basilar, fundamental, en el seno de la acción pastoral norma del episcopado [...] para que el entero cuerpo eclesial y cada una de las iglesias locales cooperen de una manera eficaz, permanente y orgánica, con pleno sentido de unidad y de universalidad con la actividad misionera de la Iglesia (Pablo VI, 1972a).

En el mismo discurso también expresaba su deseo de "una más metódica, concorde y universal animación misionera del pueblo de Dios" (Pablo VI, 1972a).

En el mensaje para la Jornada Mundial de las Misiones de 1972, afirma que la cooperación con las misiones es deber de todos los cristianos y que la jornada no puede quedar reducida a un día, sino que tiene que ser compromiso constante; se pregunta si la asfixia espiritual de la Iglesia no tiene que ver con la falta de auténtico espíritu misionero, citando Apostolicam actuositatem: "es tanta la conexión y trabazón de

3 En una obra anterior (1969), Echenique presenta, desde esta mirada, la labor de las OMP con base en tres importantes documentos del beato Pablo VI difundidos en Pentecostés del año 1972: El mensaje para la Jornada Mundial de las Misiones, la homilía de Pentecostés en la misa celebrada en el Colegio Sacerdotal del Clero Indígena y el discurso a la Asamblea General de los Directores Nacionales de las OMP. Posteriormente, Goiburu (1985), seguirá una línea similar.

4 En la primera parte, Los precedentes históricos de la situación actual, Esquerda (2000) ofrece un recorrido por la contribución de los principales actores de la animación y cooperación misioneras: las OMP, las instituciones misioneras, las iglesias particulares y otras iniciativas. 
los miembros en este Cuerpo (cf. Ef., 4,16), que el miembro que no contribuye según su propia capacidad al aumento del cuerpo debe reputarse como inútil para la Iglesia y para sí mismo" (Concilio Vaticano II, 1965b, 2).

Anteriormente, dirigiéndose al Capítulo General del Pontificio Instituto Misiones Extranjeras (PIME), el 21 de enero de 1972, Pablo VI les había dicho:

Por este motivo hemos apreciado mucho el compromiso tomado por vuestro Capítulo de cooperar siempre más con las iglesias locales, reforzando los vínculos vitales entre los misioneros y los obispos, los presbíteros y los fieles de esas iglesias, de manera que se promueva una animación misionera cada vez más acentuada (Pablo VI, 1972b).

Hay que tener en cuenta que el PIME, en 1961, ya había dado nombre a su sede de Milán como Centro de Cultura y Animación Misionera ${ }^{5}$. Este hecho, como indica Esquerda Bifet (2000), está en consonancia con la tradición de los institutos misioneros que, además de enviar misioneros a los territorios de misión, se han implicado a fondo en la animación misionera (pp. 196-197); la RMi, en consecuencia, constata "la validez y la actualidad de la vocación misionera específica de estos Institutos, que todavía "continúan siendo muy necesarios» (Juan Pablo II, 1990, 27), no solo para la actividad misionera ad gentes, como es su tradición, sino también para la animación misionera, tanto en las iglesias de antigua cristiandad, como en las más jóvenes.

Más tarde, el 31 de mayo de 1974, la Sagrada Congregación para la Propagación de la Fe fundó el Centro Internacional de Animación Misionera (CIAM):

En el intento de crear una institución permanente y orgánica en memoria de las celebraciones arriba mencionadas, ejecutando las deliberaciones de la Asamblea plenaria de la S. Congregación tenidas en marzo de 1974, y en el espíritu del Año santo de 1975, que según los deseos del Sumo Pontífice Pablo VI debe ser también un año misionero, el Cardenal Prefecto Agnelo Rossi ha querido, con decreto del 31 de mayo de 1974, constituir un "Centro Internacional de Animación Misionera", dependiente de la S. Congregación, con sede en el estudiantado del Colegio S. Pedro Apóstol. El fin específico del Centro es aquel de la formación de responsables del espíritu misionero a nivel internacional, de futuros animadores de personas e instituciones en sus países (Metzler, 1976, p. 132).

Mons. Juan Esquerda Bifet (2019b) ofrece su testimonio personal de la creación del CIAM, ya que fue su primer director y estuvo en el cargo hasta el año 2000. La creación del CIAM fue seguida, el 3 de diciembre de 1974, por la creación, en Burgos, del Instituto de Misionología y Animación Misionera "P. José Zameza", como relata Calvo Pérez (2007).

5 En diciembre de 1969, la Conferencia Episcopal Italiana aprobó un estatuto para los centros misioneros, que fueron creados en casi todas las diócesis; a raíz de la publicación de las Normas para la coordinación de las actividades y para la animación misionera de las diócesis por la Comisión Episcopal para la cooperación entre las Iglesias el 27 de marzo de 1974, muchos pasaron a llamarse centros de animación misionera. 
El mismoPabloVI, posteriormente, en el mensaje para laJornada Mundial delas Misionesde 1977 yrecordando loqueya había escrito en la Evangelii nuntiandisobrela necesidad dela preparación delos agentes dela evangelización (Pablo VI, 1975, 73), insiste en la urgencia de "apóstoles propiamente formados para la misión ad gentes" (Pablo VI, 1977); para ello, deben poseer "un marcado sentido universalista, fruto de fina sensibilidad humana y eclesial" (ibid.). En él se dan diversas orientaciones para la formación misionera a todos los niveles "desde la primera catequesis sacramental hasta el estudio de la teología" (ibid.); la formación debe ser teórica, así como espiritual y "especialmente, mediante el vivo contacto con quien ejercita la misión y conoce, por experiencia directa, sus exigencias y problemas" (ibid.). Para conseguir este fin, Pablo VI confiaba en que no faltaran "positivas iniciativas para instituir o consolidar los centros de estudio y de animación misionera” (ibid.).

Con base en esta petición del papa, el Secretariado Internacional de la Pontificia Unión Misional (PUM) desarrolló en Roma un curso de formación misionera para animadores del pueblo de Dios. Mons. Esquerda Bifet en la introducción al curso, insiste en la necesidad de formación de animadores del espíritu misionero de todo el pueblo de Dios ya que él constata que se ha perdido el sentido de misión ad gentes puesto que la misión se muestra centrándose en aspectos marginales que no constituyen la misión en sí misma, pues trata de aspectos de desarrollo humano o social, sin entrar en el núcleo espiritual de la misma ${ }^{6}$. Por eso afirma: "El término misión ha sufrido una inflación enfermiza. A todo se llama misión y animación misionera" (Esquerda Bifet, s.f., 11); todo lo cual "lleva también a una distribución de las ayudas que no resulta muy adecuada" (Esquerda Bifet, s.f., 11). La conclusión, para Esquerda Bifet es clara: "De todo ello se desprende la necesidad urgente de formación misionera en los responsables de la animación misionera del pueblo de Dios" (s.f., p. 12)7.

Profundizando en el concepto, Mons. Esquerda y el P. Dinh Duc Dao (Esquerda Bifet \& Dao, s.f.) dicen:

Animación misionera significa tratar la vocación cristiana, la vida consagrada y la vida sacerdotal en una actitud de disponibilidad para la misión universal. Todo el Pueblo de Dios y cada uno según la propia vocación debe sentirse responsable de la evangelización ad gentes y sin fronteras (p. 112).

Los autores manifiestan, también, el sentido práctico de la animación misionera: "La verdadera animación lleva a una cooperación eficaz" (p. 112) y describen su finalidad como "impregnar a todo el Pueblo de Dios de espíritu misionero" (p. 112).

Ciertamente, las iniciativas reseñadas aquí en el ámbito universal y pontificio son solo una pequeña muestra de la amplia e intensa actividad de animación misionera que se ha desarrollado en las diócesis de todo el mundo en los ańos siguientes al Concilio Vaticano II. Esto como aplicación de sus principios y directrices, así como el empeño de los institutos misioneros en la difusión de la información misionera,

6 Hay que recordar que, en ese momento, este era un tema candente, como se comprueba en Animazione missionaria e promozione umana oggi (1976); de hecho, es uno de los trasfondos de la Evangelii nuntiandi (Pablo VI, 1975, 31-33).

7 Esta crisis de la animación misionera, que ya constata Esquerda en su momento, se fue agravando, explica Gheddo (1989). Todo lo cual motiva la publicación, por parte de san Juan Pablo II, de la encíclica Redemptoris missio. 
en la formación y la promoción de las vocaciones misioneras. A todo ello habría que sumar las, también innumerables, iniciativas de los fieles (grupos, asociaciones, voluntariado solidario y misionero, jornadas, eventos, etc.).

\section{El magisterio del papa Francisco}

El recorrido por el magisterio de los anteriores pontífices ofrece el marco adecuado para comprender el del papa actual, puesto que Francisco no considera que ofrezca una novedad absoluta, sino que se siente deudor de sus predecesores y continuador de su obra, como pone de manifiesto citando su magisterio, siempre que se ofrece la ocasión. La gran novedad del papa Francisco reside, tal vez, más en la forma que, propiamente, en los contenidos. Sin lugar a duda, a ello contribuye el hecho de ser latinoamericano, así como su ministerio pastoral; así, aplica con frecuencia a la Iglesia universal los contenidos y la metodología de la conferencia general de Aparecida (2007) del Consejo Episcopal Latinoamericano (CELAM) y el respectivo documento conclusivo ${ }^{8}$.

Se debe hacer notar que en el magisterio del papa Francisco no se encuentra un concepto articulado de animación misionera porque, para él, toda la actividad pastoral de la Iglesia está orientada a formar "discípulos misioneros" (Francisco, 2013a, 24). De hecho, una de las cosas más notables de Francisco es su hincapié en la continuidad entre pastoral y misión. Se puede, pues, afirmar que, para él, toda la pastoral tiene el tinte de animación misionera. Francisco no puede concebir una pastoral sin el horizonte hacer llegar el testimonio y el anuncio de Jesucristo a todos, especialmente a los más alejados de Cristo y de la Iglesia.

\subsection{La Evangelii Gaudium}

En su exhortación apostólica Evangellii Gaudium (Francisco, 2013a; EG), el Papa invita a "una nueva etapa evangelizadora" (1) caracterizada por la "alegría del evangelio" (ibid.). Ello implica "un determinado estilo evangelizador" (18) que Francisco invita "a asumir en cualquier actividad que se realice" (ibid.). Los números introductorios a la exhortación apostólica delinean un preciso programa de renovación pastoral que se puede calificar, sin dudar, de misionero.

La alegría se opone a "la tristeza individualista que brota del corazón cómodo y avaro, de la búsqueda enfermiza de placeres superficiales, de la conciencia aislada” (3). Para ello, hay que permitir a Dios que "que nos lleve más allá de nosotros mismos para alcanzar nuestro ser más verdadero" (8), es vivir a "un nivel superior" (10), el de dar la vida por los otros (ibid.). Por tanto, el fundamento de todo es el encuentro con Jesucristo (3) ya que sólo Dios "que manifestó su amor inmenso en Cristo muerto y resucitado" (11) "es capaz de renovar" (ibid.), ya que:

8 Parece evidente que la llamada a la misión que hace Francisco a toda la Iglesia universal es la ampliación del "compromiso de una gran misión en todo el continente" (Consejo Episcopal Latinoamericano, 2007, 362), que asumen los obispos del CELAM. 
La verdadera novedad es la que Dios mismo misteriosamente quiere producir, la que Él inspira, la que Él provoca, la que Él orienta y acompańa de mil maneras. En toda la vida de la Iglesia debe manifestarse siempre que la iniciativa es de Dios, que 'Él nos amó primero' (1 Jn 4,19) y que 'es Dios quien hace crecer' $(1 \mathrm{Co} 3,7)(12)$.

Con referencia a la XIII Asamblea General Ordinaria del Sínodo de los Obispos sobre el tema La nueva evangelización para la transmisión de la fe cristiana, el Papa recuerda que: "que la nueva evangelización convoca a todos y se realiza fundamentalmente en tres ámbitos" (14): la pastoral ordinaria, los que no viven de acuerdo con el evangelio y los que no conocen a Jesucristo o lo han rechazado. Es significativo que el uso que el Papa hace del concepto nueva evangelización no sea su acepción usual - una de las formas que adquiere la actividad pastoral—, que se restringe al segundo campo de los indicados como necesitados de nueva evangelización, sino que amplía su significación.

El Santo Padre usa la expresión nueva evangelización con un nuevo matiz que se corresponde con la intención de la EG: llenarlo todo con "la alegría del evangelio" (2013a, 1). "El Evangelio, donde deslumbra gloriosa la Cruz de Cristo, invita insistentemente a la alegría" (5), su centro es el encuentro con Jesucristo (7) y como "toda experiencia auténtica de verdad y de belleza busca por sí misma su expansión" (9). El Papa repite con san Pablo: “"¡Ay de mí si no anunciara el Evangelio!» (1 Co 9,16)” (ibid.). Hacen falta, pues, "ministros del Evangelio, cuya vida irradia el fervor de quienes han recibido, ante todo en sí mismos, la alegría de Cristo (Pablo VI, 1975, 80)" (Francisco, 2013a, 10). Más adelante, el apartado que lleva por título Una eterna novedad" (11-13), hace una descripción precisa de cómo el Evangelio renueva a los fieles y a la Iglesia y, en consecuencia, la acción evangelizadora, que, si es auténtica, es siempre "nueva" (11).

En resumen, para Francisco, nueva evangelización es poner el Evangelio en el centro de todo y, de esta manera, todo se hace nuevo ${ }^{9}$. Como el Evangelio invita a mirar más allá de nosotros mismos y es, de por sí, universal, la nueva evangelización no puede ser menos que misionera. En coherencia con la llamada del Evangelio a la conversión —a la que también apuntaba san Juan Pablo $\mathrm{II}^{10}$ —, el papa Francisco espera "que todas las comunidades procuren poner los medios necesarios para avanzar en el camino de una conversión pastoral y misionera” (Francisco, 2013a, 25) y expone, largamente, en qué sentido la desea (25-33).

Desde la perspectiva pedagógica, resalta que en el apartado intitulado Todos somos discípulos misioneros (119-121), el Papa recuerde que el compromiso evangelizador de cualquier discípulo misionero surge del encuentro con el amor de Dios:

9 En el discurso a la Asamblea general de las OMP de 1 de junio de 2018, el Papa hizo un llamamiento a "dar una nueva impronta evangélica a la misión de la Iglesia en el mundo" (2018a); qué duda cabe que es extensible a toda la labor pastoral ordinaria y misionera de la Iglesia. En este mismo sentido, es de gran interés el discurso de Francisco (2020a) que tenía preparado para este ańo, y que no pudo dar por la crisis del coronavirus. Su análisis aquí desbordaría la intención de este artículo.

10 "Es necesaria una radical conversión de la mentalidad para hacerse misioneros y esto vale, tanto para las personas, como para las comunidades" (Juan Pablo II, 1990, 49). 
Que nadie postergue su compromiso con la evangelización, pues si uno de verdad ha hecho una experiencia del amor de Dios que lo salva, no necesita mucho tiempo de preparación para salir a anunciarlo, no puede esperar que le den muchos cursos o largas instrucciones (120).

El entusiasmo que Dios infunde en el cristiano no quiere decir que no haya necesidad de una adecuada formación para crecer como evangelizadores, pues esta debe ser integral y práctica, comunitaria y recíproca: "Procuramos al mismo tiempo una mejor formación, una profundización de nuestro amor y un testimonio más claro del Evangelio" (121), así como dejar que "los demás nos evangelicen constantemente" (ibid.).

\subsection{Mensajes para la Jornada Mundial de las Misiones hasta 2019}

En el mensaje para el año 2013, el Papa resalta que las OMP:

Tienen como propósito animar y profundizar la conciencia misionera de cada bautizado y de cada comunidad, ya sea reclamando la necesidad de una formación misionera más profunda de todo el Pueblo de Dios, ya sea alimentando la sensibilidad de las comunidades cristianas a ofrecer su ayuda para favorecer la difusión del Evangelio en el mundo. (Francisco, 2013b).

El siguiente año, 2014, el mensaje se centró en la alegría. Por eso, el Papa cita a san Pablo: "Dios ama al que da con alegría" (Francisco, 2014). La consecuencia que extrae es que es necesario "reavivar el deseo y el deber moral de la participación gozosa en la misión ad gentes" (Francisco, 2014). Siguiendo la lógica de la alegría del evangelio, Francisco afirma que:

La contribución económica personal es el signo de una oblación de sí mismos, en primer lugar al Señor y luego a los hermanos, porque la propia ofrenda material se convierte en un instrumento de evangelización de la humanidad que se construye sobre el amor (Francisco, 2014).

El mensaje del año 2015 estaba centrado en el Año de la Vida Consagrada. El Papa aprovecha para resaltar que: "La misión de los servidores de la Palabra —obispos, sacerdotes, religiosos y laicos— es la de poner a todos, sin excepción, en una relación personal con Cristo" (Francisco, 2015b), por tanto, "todo bautizado está llamado a vivir lo mejor posible su compromiso, según su situación personal" (Francisco, 2015b). Y, ya que el año 2016 fue el Año de la Misericordia, en el correspondiente mensaje, el Santo Padre insiste en la necesidad de ensanchar el corazón para que sea universal: "No permitamos que nuestras preocupaciones particulares encojan nuestro corazón, sino que lo ensanchemos para que abarque a toda la humanidad" (Francisco, 2016).

La misión en el corazón de la fe cristiana es el título del mensaje del año 2017. En él, Francisco resalta el papel de las OMP: "para suscitar en cada comunidad cristiana el deseo de salir de sus propias fronteras y sus seguridades, y remar mar adentro para anunciar el Evangelio a todos" (Francisco, 2017b). Para ello, el Papa propone como punto de partida "una profunda espiritualidad misionera" (Francisco, 2017b) y "un compromiso constante de formación y animación misionera" (Francisco, 2017b) para que "crezca en cada uno un corazón misionero" (Francisco, 2017b). 
A los jóvenes, en el mensaje del año 2018, les recuerda que "la vida es una misión" (Francisco, 2018). El Papa hace ver la coincidencia del octubre misionero con el Sínodo dedicado a ellos, por eso dice: "será una nueva oportunidad para hacernos discípulos misioneros, cada vez más apasionados por Jesús y su misión, hasta los confines de la tierra" (Francisco, 2018).

\subsection{La Carta de convocatoria del mes misionero extraordinario de octubre de 2019}

La carta del papa Francisco al Cardenal Filoni, convocando el mes misionero extraordinario, es de un interés extraordinario para comprender el pensamiento misionero del Papa y cómo piensa realizarlo en la práctica pastoral. Especialmente resaltan tres párrafos.

En uno habla de las tentaciones que impiden abrirse "a la gozosa novedad del Evangelio" (Francisco, 2017a); estas son: la "introversión eclesial", "la clausura autorreferencial en la seguridad de los propios confines", el "pesimismo pastoral” y la "nostalgia estéril del pasado" (Francisco, 2017a).

En otro, es de destacar la convocatoria del mes misionero extraordinario como medio para conseguir: "despertar aún más la conciencia misionera de la missio ad gentes y de retomar con un nuevo impulso la transformación misionera de la vida y de la pastoral” (Francisco, 2017a), o sea:

Que todos los fieles lleven en su corazón el anuncio del Evangelio y la conversión misionera y evangelizadora de las propias comunidades; para que crezca el amor por la misión, que "es una pasión por Jesús, pero, al mismo tiempo, una pasión por su pueblo” (Francisco, 2013a, 268) (Francisco, 2017a).

En el último, la forma concreta de conseguir el fin, es:

Promover iniciativas e intensificar de manera especial la oración —alma de toda misión—, el anuncio del Evangelio, la reflexión bíblica y teológica sobre la misión, las obras de caridad cristiana y las acciones concretas de colaboración y de solidaridad entre las Iglesias, de modo que se avive el entusiasmo misionero y nunca nos lo roben" (Francisco, 2017a).

Hay que hacer notar que, junto a los medios tradicionales de la animación, formación y cooperación misionera, el Papa introduce aquí dos grandes novedades dignas de ser tenidas en cuenta: cita como medios específicos para la animación misionera el anuncio del evangelio y las obras de caridad cristiana. Este hecho, hay que decir, está en plena sintonía con la Evangelii Gaudium, en la que les dedica sendos capítulos, el tercero (El anuncio del evangelio) y el cuarto (La dimensión social de la evangelización).

\subsection{El Mensaje para la Jornada Mundial de las Misiones de 2020}

El mensaje lleva por título: "Aquí estoy, envíame" (Francisco, 2020b). Está, pues, centrado en la dinámica de vocación divina y respuesta humana. El Papa afirma que es: "la respuesta siempre nueva a la pregunta del Señor: ‘¿A quién enviaré?’. Esta llamada viene del corazón de Dios, de su misericordia, que interpela tanto a la Iglesia como a la humanidad en la actual crisis mundial" (Francisco, 2020b). 
En su mensaje, el Papa propone continuar el programa, impulsado por el mes misionero extraordinario, cuyo lema era: "Bautizados y enviados: la Iglesia de Cristo en misión en el mundo" (Francisco, 2020b). Este programa coincide con el plan global de su pontificado: "la conversión misionera" (Francisco, 2013a, 30). Para ser real tiene que darse en las concretas circunstancias que estamos viviendo todos, "la actual crisis mundial" (Francisco, 2020b). El Papa las ve como una interpelación, desde la realidad, que se convierte en una propuesta de salida misionera. En este contexto se da:

La llamada a la misión, la invitación a salir de nosotros mismos por amor de Dios y del prójimo [...] La misión que Dios nos confía a cada uno nos hace pasar del yo temeroso y encerrado al yo reencontrado y renovado por el don de sí mismo (Francisco, 2020b).

En este mensaje, el Papa centra la misión de la Iglesia en el misterio pascual y en Pentecostés. Así, toda la vida cristiana se entiende como vocación: "Dios siempre nos ama primero y con este amor nos encuentra y nos llama" (Francisco, 2020b). En el mensaje, el Papa vuelve sobre la idea, tan suya, de que la vocación tiene su origen en la dignidad humana: "Haber recibido gratuitamente la vida constituye ya una invitación implícita a entrar en la dinámica de la entrega de sí mismo" (Francisco, 2020b). Por el bautismo esta semilla madura "como respuesta de amor en el matrimonio y en la virginidad por el Reino de Dios", ya que "la vida humana nace del amor de Dios, crece en el amor y tiende hacia el amor". "La misión es una respuesta libre y consciente a la llamada de Dios" si bien la llamada a salir, a la misión, solo se percibe cuando vivimos "una relación personal de amor con Jesús vivo en su Iglesia” (Francisco, 2020b).

En conclusión, se puede decir, sin temor a exagerar, que en este mensaje se encuentra todo un programa de animación misionera de la pastoral para lograr la conversión misionera personal de los bautizados y la Iglesia en su conjunto. La conciencia de la vida como una llamada a la entrega de sí mismo; el bautismo como la ayuda de la gracia de Dios para una respuesta más generosa con entrega total de la vida; la posibilidad de responder en la Iglesia "en la vía del matrimonio como de la virginidad consagrada o del sacerdocio ordenado" (ibid.); la disponibilidad de cualquier bautizado para ser enviado a cualquier lugar; la profunda solidaridad entre los seres humanos del mundo entero; y, por último, la necesidad de responder a Dios en las circunstancias concretas del mundo y de la Iglesia.

\subsection{Claves del papa Francisco para la animación misionera de la pastoral}

De la lectura de conjunto de la síntesis expuesta del magisterio del papa Francisco se pueden extraer una serie de consecuencias interesantes para la práctica de la animación misionera de la pastoral.

- La renovación en la vida del cristiano y de la Iglesia solo puede venir desde el mismo evangelio; es necesaria una nueva evangelización que consiste en dar "nueva impronta evangélica" (Francisco, 2018a) a la vida y a la misión de la Iglesia. Es decir, de poner el kerigma —el encuentro con Jesucristo— en el centro de la vida del bautizado, de las comunidades cristianas y de la Iglesia. Esquerda Bifet (2019a), apunta que, la espiritualidad misionera implica una constante conversión personal, comunitaria y de las estructuras (pp. 344, 346).

- El origen de la misión está en el bautismo — más aún, en la llamada a la existencia—, de ahí la alegría que produce realizar la vida en apertura a los demás. La formación cristiana debe tener como finalidad 
hacer fructificar la gracia del bautismo y avivar la conciencia misionera para comprender la importancia de vivir la vida en clave de vocación y de misión, como apertura y entrega constantes a las personas, a la humanidad y a la Iglesia ${ }^{11}$.

- A los medios tradicionales de la animación misionera, el Papa añade la participación en el anuncio del evangelio y el ejercicio concreto de la caridad cristiana. Es decir, las motivaciones profundas de fe en Cristo y de auténtica vida cristiana como motor de la misión. Testimonio y caridad no pueden ser considerados simples medios para la misión, entendida esta como propagación de la doctrina cristiana. Ciertamente el Concilio Vaticano II ya invita a "vivir profundamente la vida cristiana" (1965a, 36), porque la oración, el testimonio y la caridad es obligación de todo cristiano y afirma que de este modo Dios fecunda con su gracia la obra misionera (ibid.). El papa Francisco abunda en esta doctrina tradicional, aunque se puede decir que en su insistencia en esto radica, probablemente, la gran novedad — en la forma y el fondo — de origen latinoamericano que ofrece su magisterio.

- Hay una profunda sinergia entre misión y pastoral: La misión universal es el paradigma de toda la pastoral, por lo que esta debe mirar hacia la actividad misionera para encontrar aliento e inspiración; del mismo modo, la pastoral —asumiendo la misión como eje transversal— amplía su horizonte, su radio de acción y sus motivaciones, proporciona a la misión universal los medios necesarios para que no se detenga, para que salga hacia las periferias y alcance la realidad universal de toda la humanidad ${ }^{12}$. Corresponde a todos los que tienen responsabilidad en la Iglesia, ponerse al servicio de los demás para que estos desarrollen su vocación misionera.

- La participación de todo el pueblo de Dios en la misión significa potenciar la sinodalidad en la Iglesia, entendiendo esta como un instrumento de atención al Espíritu en la escucha recíproca entre todos los bautizados y, por tanto, un método privilegiado de discernimiento espiritual y pastoral orientado a la misión universal, como afirman Martínez Sáez (2020) y Bueno de la Fuente (2020).

En resumen, se puede afirmar que el pontificado de Francisco se puede contemplar como el punto de llegada de una larga trayectoria a lo largo de la cual se ha ido definiendo, en la práctica y en la teoría, qué es la animación misionera, cómo se desarrolla y cómo debe incluirse en la pastoral ordinaria de manera cordial. No es, sin embargo, un punto final, sino un punto de partida el cual debería ser evidente para todos en la Iglesia - como lo es para el Papa—. A saber, que es imposible una pastoral en la Iglesia que no sea esencialmente católica, universal, abarcando la realidad humana de manera integral hacia el inicio de una nueva etapa evangelizadora. La forma en que lo hace Francisco, con un lenguaje no verbal fuertemente expresivo, es también un elemento que hay que considerar como una importante aportación: la actividad evangelizadora de la Iglesia debe llevar, indispensablemente, la marca de la alegría.

11 "Llegamos a ser plenamente humanos cuando somos más que humanos, cuando le permitimos a Dios que nos lleve más allá de nosotros mismos para alcanzar nuestro ser más verdadero. Allí está el manantial de la acción evangelizadora” (Francisco, 2013a, 8).

12 Incluyendo la "casa común" que la humanidad habita, como resalta la carta encíclica Laudato si' (Francisco, 2015a). 


\section{Conclusiones}

El recorrido que se ha ofrecido por el magisterio pontificio ha indagado sobre el uso del concepto de animación misionera y su puesta en práctica en la pastoral. Se debe constatar que la investigación es incompleta, provisional y muy sucinta; aun así, permite sacar las siguientes conclusiones que pueden ser útiles en la investigación teológica y en la práctica pastoral:

1. La necesidad de la transmisión de la fe está enraizada en la misma conciencia cristiana católica; con este propósito, se funda en 1622, en Roma, una Sagrada Congregación cuyo nombre en latín, Propaganda Fide, recuerda que es una obligación.

2. A principios del s. XX, con el arribo de la difusión social a través de medios de comunicación modernos —en ese momento muy primitivos_-, la palabra propaganda adquiere un uso profano muy difundido; en la Iglesia católica se usa para designar la propaganda apostólica, en general, y misional, en particular. De hecho, en esta época, muchas publicaciones llevaban el título de propaganda misional. Un aspecto importante en el magisterio, y entre quienes se dedicaron a la propaganda misional, es la intención de que la urgencia de la misión calara en la mentalidad del creyente. Para ello, los papas eligen a las OMP como el medio privilegiado de animación y cooperación misionera.

3. En ese contexto eclesial, la propaganda es, pues, un medio pastoral y nunca, meramente, proselitista. Está al servicio de la pastoral misionera. Esta es llevada a cabo por animadores misioneros. Estos son los propios misioneros cunado vuelven a sus países de origen, así como otros agentes pastorales específicos. El objetivo es infundir el espíritu misionero y despertar la dimensión misionera del bautismo en todos los cristianos. El reconocimiento de la dimensión espiritual de la pastoral misionera — más aún, de la acción del Espíritu Santo en la Iglesia, en la misión y en la pastoral- es crucial desde la carta encíclica de Pío XII, Mystici Corporis Christi (1943). De hecho, es frecuente encontrar en la bibliografía de la época el binomio espiritualidad y animación misionera.

4. El decreto Ad gentes del Concilio Vaticano II opera un cambio sustancial en el concepto de misión, en general, y ad gentes, en particular: la cooperación misionera ya no se reduce a la cooperación con las misiones, pues su cometido es más amplio: todo el pueblo de Dios tiene "responsabilidad en la difusión del Evangelio" (1965a, 35). Por ello, el decreto pide que todos "acepten su cometido en la obra misional entre los gentiles" (1965a, 35).

5. Después del Concilio Vaticano II se empieza a difundir el concepto de animación misionera que, poco a poco se va perfilando y definiendo, hasta pasar a ser de uso común, ayudado por la práctica cada vez más difundida del concepto. Este alcanza su expresión más lograda durante el magisterio de san Juan Pablo II, quien hace abundante uso de él.

6. En el magisterio del papa Francisco no aparece la expresión animación misionera. Este hecho no quiere decir que no tenga una profunda preocupación por promover la conciencia misionera en el pueblo de Dios. Todo lo contrario, el papa Francisco toma el sentido profundo de la animación misionera desde sus raíces y apela a la necesidad de infundir el Espíritu en la Iglesia para impulsar la nueva evangelización de la Iglesia, crear una mentalidad (cultura) misionera y que haya "evangelizadores con 
Espíritu” (2013a, cap. V), éstos, para él, son todos los bautizados, en cuanto discípulos misioneros (2013a, 119-121) y, por tanto, todo el Pueblo de Dios (2013a, 111-134).

7. Cada vez se hace mayor énfasis en que la caridad sincera, el amor misericordioso, la cordialidad, la ternura... son elementos esenciales de la vida y de la misión del cristiano. La caridad divina es "el alma de la misión" (Benedicto XVI, 2006); sin ella, la misión se convierte en mera filantropía y la Iglesia en una especie de ONG; la caridad fundamenta la comunión de la Iglesia que se traduce en sinodalidad, salida a las periferias y universalidad.

8. A inicios de siglo XIX, un gran fervor misionero en el pueblo de Dios impulsó la misión universal de la Iglesia; ello dio lugar al envío de muchos misioneros, supuso el origen de las obras misionales y de muchos institutos misioneros. Desde entonces, el protagonismo en la animación misionera se ha ido ampliando, desde los inicios carismáticos de las OMP y los institutos misioneros, al de las iglesias particulares — diócesis y conferencias episcopales - además de las numerosas iniciativas surgidas en el pueblo de Dios para la animación y cooperación misionera.

9. El magisterio pontificio ha acompañado este proceso: por un lado, ha sido receptivo a las iniciativas carismáticas del pueblo de Dios y ha ayudado en su discernimiento, maduración y crecimiento. Por otro lado, el papa — pastor de la Iglesia universal — ha ayudado, con su magisterio, a que se difunda una amplia conciencia de la responsabilidad misionera de todos. La Comisión Teológica Internacional, que explica la circularidad todos-algunos-uno (2018, 106 a), se muestra, en este caso concreto, como un importante motor para la misión universal, como paradigma de la comunión misionera y de la sinodalidad.

10. También se ha dado un proceso similar en la reflexión teológica, aunque es necesario seguir fomentando en la teología la integración más profunda de que "la Iglesia peregrinante es misionera por su naturaleza" (Concilio Vaticano II, 1965a, 2). Así, la misión no será considerada como un apéndice de la teología y, menos aún, de la pastoral (sea la teología pastoral, sea la actividad pastoral), acabando así con la dicotomía entre teoría y práctica: En palabras de Meroni: "La necesidad experiencial y teológica de refundar y entender mejor la lógica sacramental de evento Jesucristo, de su Encarnación y de su Pascua" (2019, p. 77). Además, si la misión es el eje vertebrador de la reflexión teológica, la pastoral misionera constituirá, viceversa, un acicate para profundizar en el misterio de la fe en Cristo de la Iglesia.

11. La Iglesia en América latina, hoy, está embarcada en la gran misión continental que pidieron realizar los obispos en la Conferencia de Aparecida. La elección del papa Francisco ha trasladado a la Iglesia universal esta visión de Iglesia en estado de misión, de pueblo de Dios en camino, que han tenido, desde hace ańos, los obispos del CELAM. Ya la Conferencia de Puebla constataba la dificultad de la Iglesia en América latina para abrirse a los horizontes de la misión ad gentes (Consejo Episcopal Latinoamericano, 1979, 368). Desde ella aparece el despertar a la misión universal dando pasos en cuanto a la conciencia de la misión ad gentes a través de los congresos americanos de misiones y gracias a la reflexión teológica. Muchos años más tarde, en la Conferencia de Aparecida, los obispos del CELAM siguen instando a "entrar en una nueva primavera de la misión ad gentes" (Consejo Episcopal Latinoamericano, 2007, 379) y a "compartir nuestros dones espirituales, humanos y materiales con otras Iglesias" (ibid.). Con este fin animan a la animación y cooperación misionera a través de centros 
misioneros nacionales, las OMP y otros organismos (Consejo Episcopal Latinoamericano, 2007, 378). El testimonio del ministerio petrino de Francisco — de profunda impronta latina — invita a considerar cómo tiene que realizarse la misión de la Iglesia. En el Documento de Puebla los Obispos afirmaban: "debemos dar desde nuestra pobreza" (Consejo Episcopal Latinoamericano, 1979, 368) y la idea se retoma más tarde en Aparecida (Consejo Episcopal Latinoamericano, 2007, 379). Francisco ofrece a la Iglesia universal (y al conjunto de toda la humanidad), un concepto de misión aparentemente "pobre" en sus apariencias, pero, sin embargo, muy rico y profundo, espiritual y existencial, a la vez. La Iglesia en América Latina está llamada a potenciar lo que ya vive, de forma espontánea, en referencia a la misión, desde su idiosincrasia latinoamericana. La invitación de la Conferencia de Aparecida es clara: "compartir nuestros dones espirituales, humanos y materiales con otras Iglesias" (Consejo Episcopal Latinoamericano, 2007, 379). Compartir, por un lado, — como lo hace el papa Francisco y muchos laicos, religiosas y sacerdotes - con las iglesias de más antigua evangelización, que necesitan revitalizarse y, por otro, llegar a las personas y pueblos que no conocen a Cristo (Consejo Episcopal Latinoamericano, 2007, 376. 548).

Al inicio del nuevo milenio, en su carta apostólica Novo Millennio Ineunte, san Juan Pablo II auguraba "una nueva acción misionera, que no podrá ser delegada a unos pocos 'especialistas', sino que acabará por implicar la responsabilidad de todos los miembros del Pueblo de Dios” (2001, 40). El papa Francisco, en este momento histórico de la Iglesia, pide que los protagonistas de la misión universal sean los propios bautizados y las comunidades cristianas más pequeñas y cercanas a los cristianos, empezando por la parroquia. De esta manera, impulsa la conversión misionera de toda la Iglesia. En su magisterio, ofrece los medios sencillos y asequibles para que cualquier bautizado pueda experimentar la llamada de Dios y encontrar el modo de realización de la vocación cristiana misionera. Así, nadie queda excluido en la Iglesia de participar en la misión de Cristo.

Pauline Jaricot, fundadora de la Obra Misional de la Propagación de la Fe, recibió una carta en la que, con palabras proféticas, se le alentaba a seguir, porque: "es quizá el grano de mostaza que debe producir un gran árbol cuyas ramas bienhechoras cubrirán con su sombra toda la faz de la tierra” (Naïendoff, 1995, p. 27). El sucinto recorrido hecho en este artículo muestra cómo, el grano de mostaza plantado por el esfuerzo de algunos pioneros de la animación misionera, ha ido creciendo y cobijando en sus ramas incontables iniciativas de animación y cooperación misioneras. La tarea no está concluida, porque "la misión de Cristo Redentor, confiada a la Iglesia, está aún lejos de cumplirse" (Juan Pablo II, 1990, 1). Hacer un alto y echar una mirada al camino recorrido es impulso para acometer "una nueva etapa evangelizadora marcada por esa alegría [del evangelio]" (Francisco, 2013a, 1).

\section{Referencias}

Animazione missionaria e promozione umana oggi. I Congresso Nazionale di Missiologia (Santa Maria degli Angeli-Assisi, 30 maggio-1 giugno 1975 (1976). Assisi.

Benedicto XV (1919). Carta apostólica Maximum Illud sobre la propagación de la fe católica en el mundo entero. En: Obras Misionales Pontificias, 2008, pp. 3-25. 
Benedicto XVI (2006). Mensaje para la Jornada Mundial de las Misiones 2006. Recuperado de: http://www.vatican. va/content/benedict-xvi/es/messages/missions/documents/hf_ben-xvi_mes_20060429_world-missionday-2006.html

Benedicto XVI (2007). Mensaje para la Jornada Mundial de las Misiones 2007. Recuperado de: http://www.vatican. va/content/benedict-xvi/es/messages/missions/documents/hf_ben-xvi_mes_20070527_world-missionday-2007.html

Benedicto XVI (2010). Mensaje para la Jornada Mundial de las Misiones 2010. Recuperado de: http://www.vatican. va/content/benedict-xvi/es/messages/missions/documents/hf_ben-xvi_mes_20100206_world-missionday-2010.html

Benedicto XVI (2011). Mensaje para la Jornada Mundial de las Misiones 2011. Recuperado de: http://www.vatican. va/content/benedict-xvi/es/messages/missions/documents/hf_ben-xvi_mes_20110106_world-missionday-2011.html

Benedicto XVI (2012). Mensaje para la Jornada Mundial de las Misiones 2012. Recuperado de: http://www.vatican. $\mathrm{va} /$ content/benedict-xvi/es/messages/missions/documents/hf_ben-xvi_mes_20120106_world-missionday-2012.html

Bueno de la Fuente, E. (2020). Sinodalidad desde/para la misión. En Misiones extranjeras, 292, 7-22.

Calvo Pérez, R. (2007). El Instituto de Misionología y Animación Misionera "P. José Zameza". En Misiones extranjeras,216, 131-136.

Comisión Teológica Internacional. (2018). La sinodalidad en la vida y misión de la Iglesia. Recuperado de http:// www.vatican.va/roman_curia/congregations/cfaith/cti_documents/rc_cti_20180302_sinodalita_sp.html

Concilio Vaticano II (1964). Constitución dogmática sobre la Iglesia Lumen Gentium. Recuperado de http://www. vatican.va/archive/hist_councils/ii_vatican_council/documents/vat-ii_const_19641121_lumen-gentium_ sp.html

Concilio Vaticano II (1965a). Decreto sobre la actividad misionera de la Iglesia Ad gentes. En: Obras Misionales Pontificias, 2008, pp. 145-194.

Concilio Vaticano II (1965b). Decreto sobre el apostolado de los laicos Apostolicam actuositatem. Recuperado de: http:// www.vatican.va/archive/hist_councils/ii_vatican_council/documents/vat-ii_decree_19651118_apostolicamactuositatem_sp.html

Congregación para la Evangelización de los Pueblos (1998), Instrucción Cooperatio missionalis sobre la cooperación misionera. En: Obras Misionales Pontificas (2008), pp. 533-560.

Consejo Episcopal Latinoamericano (1979). Documento de Puebla. III Conferencia General del Episcopado Latinoamericano. Recuperado de: https://www.celam.org/documentos/Documento_Conclusivo_Puebla.pdf

Consejo Episcopal Latinoamericano (2007). Documento de Aparecida. V Conferencia General del Episcopado Latinoamericano. Bogotá: CELAM-San Pablo-Paulinas.

Esquerda Bifet, J. (s.f.). Introducción: La formación misionera de los animadores del Pueblo de Dios. En Pontificia Unión Misional y Centro Internacional de Animación Misionera (Eds.), Temas actuales sobre evangelización. Roma: CIAM.

Esquerda Bifet, J. (2000). Implicaciones operativas de la animación y cooperación misionera (Contexto y contenidos de la instrucción "Cooperatio missionalis"). En Misiones Extranjeras, 177, 192-212. 
Esquerda Bifet, J. (2019a). El despertar de la conciencia misionera de la Iglesia en un cambio de época. "Os anunciamos lo que hemos visto y oído" (1Jn 1,3). En Misiones Extranjeras, 290, 335-352.

Esquerda Bifet, J. (2019b). Il cardinale Agnelo Rossi creatore del Centro Internazionale di Animazione Missionaria. Recuperado de https://compartirencristo.files.wordpress.com/2019/05/rossi-card-e-ciam.doc

Esquerda Bifet, J. \& Dao, D. D. (s.f.). Animación y cooperación misionera. En Pontificia Unión Misional \& Centro Internacional de Animación Misionera (Eds.), Temas actuales sobre evangelización. Roma: Centro Internacional de Animación Misionera.

Echenique, J. M. (1969). Pastoral de la cooperación misionera. Para formar y vivir litúrgicamente el espiritu misional. Madrid: PPC.

Echenique, J. M. (1972). La animación misionera del pueblo de Dios. Madrid: PPC.

Francisco (2013a). Exhortación apostólica Evangelii gaudium a los obispos, a los presbíteros y diáconos, a las personas consagradas y a los fieles laicos sobre el anuncio del evangelio en el mundo actual. Recuperado de http://www.vatican.va/content/francesco/es/apost_exhortations/documents/papa-francesco_esortazioneap_20131124_evangelii-gaudium.html

Francisco (2013b). Mensaje para la Jornada Mundial de las Misiones 2013. Recuperado de: http://www.vatican.va/ content/francesco/es/messages/missions/documents/papa-francesco_20130519_giornata-missionaria2013. html

Francisco (2014). Mensaje para la Jornada Mundial de las Misiones 2014. Recuperado de: http://www.vatican.va/ content/francesco/es/messages/missions/documents/papa-francesco_20140608_giornata-missionaria2014. html

Francisco (2015a). Carta encíclica Laudato si' sobre el cuidado de la casa común. Recuparado de: http://www.vatican. va/content/francesco/es/encyclicals/documents/papa-francesco_20150524_enciclica-laudato-si.html

Francisco (2015b). Mensaje para la Jornada Mundial de las Misiones 2015. Recuperado de: http://www.vatican.va/ content/francesco/es/messages/missions/documents/papa-francesco_20150524_giornata-missionaria2015. html

Francisco (2016). Mensaje para la Jornada Mundial de las Misiones 2016. Recuperado de: http://www.vatican.va/ content/francesco/es/messages/missions/documents/papa-francesco_20160515_giornata-missionaria2016. html

Francisco (2017a). Carta al Cardenal Filoni para convocar un mes misionero extraordinario de 22 de octubre de 2017. Recuperada de: http://www.vatican.va/content/francesco/es/letters/2017/documents/papafrancesco_20171022_lettera-filoni-mese-missionario.html

Francisco (2017b). Mensaje para la Jornada Mundial de las Misiones 2017. Recuperado de: http://www.vatican.va/ content/francesco/es/messages/missions/documents/papa-francesco_20170604_giornata-missionaria2017. html

Francisco (2018a). Discurso a los directores nacionales de las Obras Misionales Pontificias. Recuperado de: http:// www.vatican.va/content/francesco/es/speeches/2018/june/documents/papa-francesco_20180601_pontificieopere-missionarie.html

Francisco (2018b). Mensaje para la Jornada Mundial de las Misiones 2018. Recuperado de: http://www.vatican.va/ content/francesco/es/messages/missions/documents/papa-francesco_20180520_giornata-missionaria2018. html 
Francisco (2019). Mensaje para la Jornada Mundial de las Misiones 2019. Recuperado de: http://www.vatican.va/ content/francesco/es/messages/missions/documents/papa-francesco_20190609_giornata-missionaria2019. html

Francisco (2020a). Discurso a la Asamblea general de las OMP de 21 de mayo de 2020. Recuperado de http:// www.vatican.va/content/francesco/es/messages/pont-messages/2020/documents/papa-francesco_20200521_ messaggio-pom.html

Francisco (2020b). Mensaje para la Jornada Mundial de las Misiones 2020. Recuperado de: http://www.vatican.va/ content/francesco/es/messages/missions/documents/papa-francesco_20200531_giornata-missionaria2020. html

Gheddo, P. (1989). Quale animazione missionaria. Bologna: EMI.

Goiburu Lopetegui, J. M. (1985). Animación misionera. Vademecum. Navarra: Verbo Divino.

Juan Pablo II (1990), Carta encíclica Redemptoris missio sobre la permanente validez del mandato misionero. En: Obras Misionales Pontificias, 2008, pp. 373-468.

Juan Pablo II (2001). Carta apostólica Novo millennio ineunte al episcopado al clero y a los fieles al concluir el gran jubileo del año 2000. Recuperado de: http://www.vatican.va/content/john-paul-ii/es/apost_letters/2001/ documents/hf_jp-ii_apl_20010106_novo-millennio-ineunte.html

Martínez Sáez, J. F. (2020). La animación misionera, método pastoral para la sinodalidad de la "Iglesia en salida" misionera. En Obras Misionales Pontificias (Ed.), Bautizados y enviados. La Iglesia de Cristo en misión en el mundo (pp. 249-266). Madrid: PPC.

Meroni, F. (2019). La misión de la Iglesia y la missio ad gentes. Algunas observaciones iniciales. En Congregación para la Evangelización de los Pueblos \& Obras Misionales Pontificias (Eds.), Bautizados y enviados. La Iglesia de Cristo en misión por el mundo. Milán: San Paolo.

Metzler, J. (1976). Sacrae Congregationis de Propaganda Fide memoria rerum. 350 anni al servizio delle missioni, 16221972, Vol. III/2 (1815-1972). Rom-Freiburg-Wien: Herder.

Naïdenoff, G. (1995). Pauline Jaricot, fundadora de la Obra Misional de la Propagación de la Fe. Estella, Navarra: Verbo Divino.

Obras Misionales Pontificias (2008). La Iglesia misionera. Textos del magisterio pontificio. Madrid: BAC.

Pablo VI (1966a). Letra apostólica motu proprio Ecclesiae Sanctae por la que se promulgan normas de aplicación de algunos decretos del Concilio Vaticano II. Recuperado de http://www.vatican.va/content/paul-vi/it/ motu_proprio/documents/hf_p-vi_motu-proprio_19660806_ecclesiae-sanctae.html (en italiano)

Pablo VI (1966b). Carta apostólica Graves et increscentes a la Pontificia Unión Misional del Clero. En: Obras Misionales Pontificias, 2008, pp. 195-205.

Pablo VI (1972a). Discurso a los directores nacionales de las Obras Misionales Pontificias del 19 de mayo de 1972. Recuperado de: http://www.vatican.va/content/paul-vi/it/speeches/1972/may/documents/hf_pvi_spe_19720519_pont-opere-missionarie.html

Pablo VI (1972b). Discurso al Capítulo general del Pontificio Instituto de Misiones Extranjeras de 21 de junio de 1972. Recuperado de: http://www.vatican.va/content/paul-vi/it/speeches/1972/january/documents/hf_pvi_spe_19720121_capitolo-pime.html

Pablo VI (1975). Exhortación apostólica Evangelii nuntiandi acerca de la evangelización en el mundo contemporáneo. En: Obras Misionales Pontificias, 2008, pp. 237-305. 
Pablo VI (1977). Mensaje para la Jornada Mundial de las Misiones. Recuperado de: http://www.vatican.va/content/ paul-vi/it/messages/missions/documents/hf_p-vi_mes_19770529_world-day-for-missions-1977.html

Pío XI (1926). Encíclica Rerum Ecclesiae sobre la acción misionera. En: Obras Misionales Pontificias (2008), pp. 27-50.

Pío XII (1957). Encíclica Fidei donum sobre las misiones, especialmente en África. En: Obras Misionales Pontificias (2008), pp. 83-105.

Sagrada Congregación para el Clero (1980). Normas directivas Postquam apostoli para la colaboración de las Iglesias particulares y especialmente para una mejor distribución del clero en el mundo. En: Obras Misionales Pontificias (2008), pp. 307-336.

Sagrada Congregación para la Evangelización de los Pueblos o de Propaganda Fide (1969). Instrucción Quo aptius sobre la cooperación misional de los obispos a través de las OMP, y acerca de las iniciativas de las diócesis. En: Obras Misionales Pontificias (2008), pp. 207-214.

Santos, A. (1977). Una Misionología española de sabor Agustiniano. En Estudio Agustiniano, 2, 791-822.

Seumois, A. (1961). L'anima dell'apostolato missionario. Bologna-Milano-Parma-Torino: EMI.

Soetens, C. (1996). Pie XI et les missions. Influences et circonstances majeures (1922-1926). En Achille Ratti pape Pie XI (pp. 693-718). Roma: Publications de l'École Française de Rome. Recuperado de https://www.persee. fr/doc/efr_0223-5099_1996_act_223_1_5055

Trinchese, S. (1996). L'Opera della propagazione della fede dalla centralizzazione a Roma nel 1921 alla Mostra missionaria del 1925. En: Achille Ratti pape Pie XI (pp. 693-718). Roma: Publications de l'École Française de Rome. Recuperado de https://www.persee.fr/doc/efr_0223-5099_1996_act_223_1_5054 